\title{
Investigating the challenges related to combining BIM and Last Planner System on construction sites
}

\author{
Conrad BOTON $(\bowtie)$, Yaya PITTI, Daniel FORGUES, Ivanka IORDANOVA \\ Department of Construction Engineering, École de Technologie Supérieure, Montréal, Canada
}

Front. Eng. Manag., Just Accepted Manuscript • https://doi.org/10.1007/s42524-019-0086-4 http://journal.hep.com.cn on November 20, 2019

(C) Higher Education Press 2020

\section{Just Accepted}

This is a "Just Accepted" manuscript, which has been examined by the peer-review process and has been accepted for publication. A "Just Accepted" manuscript is published online shortly after its acceptance, which is prior to technical editing and formatting and author proofing. Higher Education Press (HEP) provides "Just Accepted" as an optional and free service which allows authors to make their results available to the research community as soon as possible after acceptance. After a manuscript has been technically edited and formatted, it will be removed from the "Just Accepted" Web site and published as an Online First article. Please note that technical editing may introduce minor changes to the manuscript text and/or graphics which may affect the content, and all legal disclaimers that apply to the journal pertain. In no event shall HEP be held responsible for errors or consequences arising from the use of any information contained in these "Just Accepted" manuscripts. To cite this manuscript please use its Digital Object Identifier (DOI(r)), which is identical for all formats of publication." 
FEM-2019052

Verso: Front. Eng. Manag.

Recto: Conrad BOTON et al. Challenges related to combining BIM and Last Planner System

https://doi.org/10.1007/s42524-019-0086-4

RESEARCH ARTICLE

Conrad BOTON, Yaya PITTI, Daniel FORGUES, Ivanka IORDANOVA

\title{
Investigating the challenges related to combining BIM and Last Planner System on construction sites
}

(C) Higher Education Press 2020

\begin{abstract}
The construction industry is facing a gradual but important transformation towards more productivity and collaboration. In this framework, two major approaches are often cited in the literature as having the potential to improve the practices in the industry: Building Information Modeling (BIM) and Lean Construction. Several scientific studies have demonstrated the synergy of these two approaches and very recent research has reported positive results from the use of software applications as support for their implementation on construction sites. However, the stakes of such integration have been very little studied. This article presents the results of a research project conducted within a general contractor firm that decided to implement BIM and Last Planner System (LPS) on its construction sites. The research uses a four-stage action research approach, including the characterization of the research issue, the establishment of an action plan, its implementation and its evaluation. Compared to recent related studies, the research is less enthusiastic. While it highlights the need for new tools to improve production planning and control, it also points to a strong resistance to change by practitioners at the site. They emphasize the necessity for adequate pre-service training and the need for new resources that can work full-time on the ongoing training of site teams. In addition, some limitations of the tool lead workers to believe that it can quickly become a factor that slows down their daily work rather than improving it. Based on the advice of professionals, the paper formulates some recommendations to the industry, the researchers and the software developers.
\end{abstract}

Keywords Building Information Modeling, Last Planner System, construction site, lean construction.

\section{Introduction}

The construction industry is generally considered to be an underperforming industry, compared to other manufacturing industries such as aerospace and automotive ( Teicholz, 2013; Boton et al., 2016; Naoum, 2016; Boton et al., 2018b). This lack of performance is reflected in particular by low productivity and frequent overruns of costs and delays (Doloi, 2012; Rahman, et al., 2013; Cheng, 2014).

Yet, in recent years, the growing adoption of new technological approaches seems to have the potential to change the game ( Shelbourn et al., 2007; AlSehaimi et al., 2014; Poirier et al., 2016). Among these approaches, Building Information Modeling (BIM) occupies an important place (Rafael et al., 2018). The early years of the BIM approach focused on the development of technological 
solutions, for example, to solve important issues such as interoperability. But rather quickly, it became clear that the added value of such an approach should reside, not only in the arrival of new technologies, but also and above all in improving the dynamics of collaboration, the integration of the supply chain and the elimination of waste. In this context, several research projects have highlighted the necessary complementarity between BIM and Lean approaches (Tauriainen et al., 2016; Saieg et al., 2018). The synergy between the two approaches has been widely discussed in the literature and the added value of such a combination has been demonstrated (Sacks et al., 2010; Arayici et al., 2011b; Hamdi and Leite, 2012; Clemente and Cachadinha, 2013). However, very little work has been devoted to the issues related to the combined software-based use of these two approaches, which, even if they are recognized as complementary, each requires a particular methodology and important means to implement.

This paper is a revised and expanded version of a paper entitled 'Combining BIM and Last Planner on construction sites: an investigation of the related challenges' presented at the 2019's edition of the Creative Construction Conference (Pitti et al., 2019). The purpose of the research work is to investigate the challenges associated with the combination of BIM and Last Planner System through the use of a dedicated software, from the practitioner's standpoint. The rest of the article is organized into four main sections. The first section presents a literature review, including similar works. The second section is dedicated to the methodology used, including the main steps of the research. The third section presents the results obtained. These results are discussed in the fourth section, which concludes the article.

\section{Related works}

In this section, we present related research works, including the main definitions and concepts, and those pertaining to building information modelling, Last Planner System and their association in construction projects.

\subsection{Definitions and main concepts}

The success of Lean principles and the perceived benefits of using it in the manufacturing industry have prompted construction stakeholders to adopt these principles (Gao and Low, 2014). According to Koskela et al. (2002), Lean Construction is a way of studying the production system by minimizing waste of materials, time and effort in order to generate maximum added value. Among the various Lean Construction techniques, LPS is one of the most popular methods of production planning and control (Berroir et al., 2015). The LPS was developed to improve the performance of construction projects by increasing the reliability of schedules and workflow (Ballard and Howell, 2004). It is also used to reduce variability and uncertainty in construction (Ballard, 1994). According to Ballard and Howell (1997) the planning process of the Last Planner system is a procedure for creating a Master Schedule, a Reversed Phase Scheduling, a Lookahead Schedule, and a Weekly Work Plan, using Lean Construction planning techniques.

Based on different authors (Ballard, 2000; AlSehaimi et al., 2014; Berroir et al., 2015; Hamzeh et al., 2015), we can summarize the main objectives of the LPS as follow: planning of the tasks in detail as they approach the date of execution; involvement of the people who will do the work in the planning; identification and removal of the constraints in advance in order to clear the way for the execution team; coordination of the teams and the business partners to make reliable promises to carry out the planned work; identification of the root causes of problems and failures for continuous improvement. The LPS is then more a pull scheduling system that draws against the traditional push scheduling system. Indeed, the LPS emphasizes worker engagement and incorporates the principle of "pull scheduling" where only work that can be done is promised by the last gliders at weekly planning meetings as opposed to conventional planning where the work that should be done is planned at weekly meetings while insisting that they will adhere to the Master Schedule (Ballard, 2000). 
Building Information Modelling (BIM) consists in the use of "a multidisciplinary object-oriented $3 \mathrm{D}$ model of the constructed facility to improve and to document its design and to simulate different aspects of its construction or its operation" (Boton et al., 2018). Thus, it focuses on the development, the use and the transfer of digital information models of a construction project to improve its design, construction and operation (The Computer Integrated Construction Research Program, 2010). BIM becomes essential for the realization of construction projects and its deployment offers both benefits and challenges in its implementation (Boton and Forgues, 2018). It is increasingly required in the execution of projects and for many clients it becomes a requirement to be fulfilled for the grant of the project. Its importance and effectiveness have been proven through several projects (Rafael et al., 2018). Additional information can be added to the three-dimensional model(s) for analyses and simulation purposes (Boton et al., 2012; Rafael et al., 2018). In this context, it is commonly agreed that 4D models are created by linking scheduling information to the $3 \mathrm{D}$ model in order to simulate the process of construction over time (Boton et al., 2013). 5D BIM models are prepared for cost management purposes (Vigneault et al., 2019). It is more and more accepted that the sixth and the seventh dimensions are related to energy analysis and assets management purposes, but it is important to note that beyond the fifth dimension (i.e. cost), there is no consensus in the literature about what each dimension represents. Lee et al. (2005) identify eight possible dimensions which notably show how $\mathrm{nD}$ modelling can increase the variety of information to be managed around BIM. These dimensions are: maintenance needs, acoustics, process, cost, energy requirements, crime deterrent features, sustainability, and people's accessibility.

\subsection{BIM and LPS association in the literature}

Previous research works have identified some synergy between BIM and LPS. The synergy can be described through the "interactions" identified by Sacks et al. (2010), the "parallel principles" between BIM and Lean Construction (Clemente and Cachadinha, 2013) or the design workflow reduction by associating BIM and LPS (Khan and Tzortzopoulos, 2014).

In 2010, Sacks et al. (2010) conducted an analysis of the interactions between BIM and Lean approaches. They noticed that "a synergy exists which, if properly understood in theoretical terms, can be exploited to improve construction processes beyond the degree to which it might be improved by the application of either of these paradigms independently". They then proposed a juxtaposition of the Lean Construction principles and the BIM functionalities, and factually identified 56 interactions (Sacks et al., 2010).

In 2014, Khan and Tzortzopoulos (2014) proposed a discussion on how the association of BIM and LPS can affect the design workflow. The discussion, based on two building design projects, used the interaction matrix developed by Sacks et al. (2010) and showed that such an association "can improve workflow in building projects through features that reduce waste". Indeed, as demonstrated by Seppänen et al. (2010), to be fully successful, the BIM adoption needs to be associated with a lean managerial approach like LPS to control. Otherwise, the implementation "can lead to inefficiencies even when the technological approach is effective" (Khan and Tzortzopoulos, 2014). More generally, the complementarity between the BIM and the Lean approaches is well recognized in the literature (Arayici et al., 2011a; Hamdi and Leite,2012; Fosse et al., 2017 ).

The case study presented by Clemente and Cachadinha (2013) identified a number of contributions of BIM to the materialization of the principles of Lean, based on the fact that the BIM methodology has parallel principles with most of the Lean Construction principles. According to Clemente and Cachadinha (Clemente and Cachadinha, 2013), the BIM model can add a needed visual dimension to the project. This visual dimension can be aligned to all the information available and the BIM features can be exported, so "the works were easily controlled and the facility management improved. This also enabled the implementation of a LPS planning approach for daily activities planning" (Clemente and 
Cachadinha, 2013). However, some limitations and constraints have been identified, including the initial cost, the know-how and the fact that BIM is a time-consuming approach.

More and more commercial softwares are being proposed, aiming at combining BIM and Lean principles, using mobile technologies. These tools include BIM 360 Plan, LeanKit, VisiLean, TouchPlan, etc. BIM 360 Plan is a collaborative 'Look Ahead Planning' tool. The master schedule can come from traditional planning tools (MS Project or Primavera). Leankit uses a virtual Kanban board, to enable the creation of a master schedule with the participation of the whole construction team, but does not offer visualization of the 3D model. VisiLean is a production management system specifically designed for planning and production control. It supports the Last Planner system workflow, including detailed constraint analysis and assignment of resources to tasks. The master schedule and the 3D model are imported into the software. It is possible to modify the imported schedule in the software; however, the 3D model serves only for visualization and cannot be modified once imported. It also allows simultaneous visualization of the Gantt and the 3D model for 4D simulation purposes. TouchPlan uses a virtual table integrated in the software, to enable the creation of a master schedule. It is also possible to import a master schedule from traditional planning software such as MS Project or Primavera. However, it does not display the 3D model.

Very few research works have been dedicated to the neutral evaluation of Lean-BIM software, especially from the perspective of the practitioners. Some of these works explored the specific technical challenges related to the quality of the BIM model, including the lack of required information or the ineffective structuration of the information in the model (Dave and Koskela, 2011; Dave et al., 2013). Other researchers reported the constraints and limitations related to the resources including the initial costs, the time-consuming aspect of BIM and the link with the existing software (Clemente and Cachadinha, 2013). These works are of course very interesting but do not provide a complete view of the challenges, especially from the practitioners' point of view. Having the perspective of the practitioners can be very helpful to effectively evaluate how the business practices are actually aligned with a software-based implementation.

\section{Materials and Methods}

\subsection{Action research as a research method}

Action research is considered as a research method that requires contact with the field and the reality. The purpose of this approach is to identify needs or problems, before establishing a strategy to achieve change objectives in response to observed problems (Bilandzic and Venable, 2011). The action research follows the four main steps as illustrated in Fig. 1: the characterization of the research issue, the establishment of an action plan, its implementation and its evaluation.

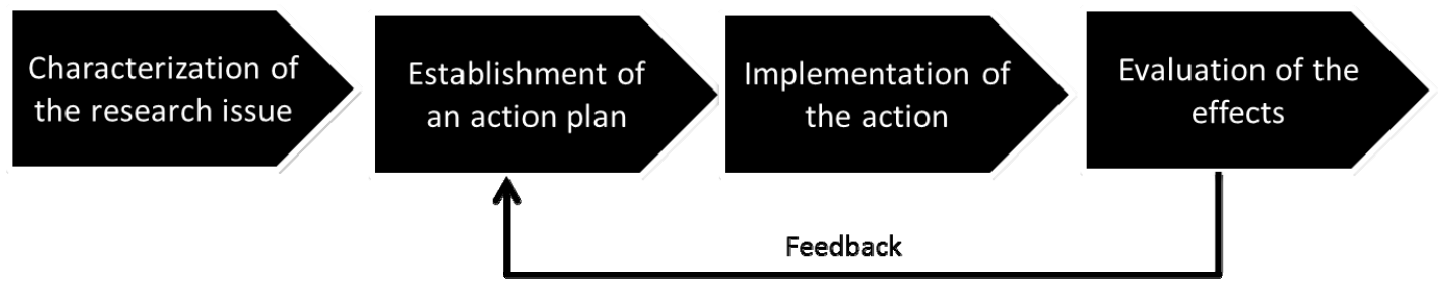

Fig. 1 The main steps of action research.

The researcher in collaboration with the industrial partner identifies the problems and the needs of the company. The problems identified are listed, categorized and submitted for research (Bilandzic and Venable, 2011). This step essentially involves establishing the first contact with the company and discussing the issues that led to the idea of the research. The establishment of an action plan consists in defining a strategy to be applied to arrive at a desired result. This action plan touches on all the issues 
identified within the company. It is part of a three-step process that includes a development phase, an implementation phase, and a monitoring and evaluation phase. The stage of implementation of the action is to put in place the action plan, which leads the researcher to act to obtain a result to the problem situation observed in the company. During the evaluation of the effects of the action, the researcher collects the data resulting from the implementation of the action plan. These data allow the researcher to evaluate the effects resulting from the implementation of the action. At the end of the action research, recommendations and lessons learned are proposed to the industrial partner as solutions to the identified problems. Solutions are derived from learning done throughout the research period. According to Bilandzic and Venable (2011), such a learning is about thinking and drawing conclusion both for the benefit of participants and as a result of research.

\subsection{The steps of the research}

Our research is anchored in the theoretical framework of action research, since our main goal is not only to change the way people work in the organization by implementing a technology, but also to study the process and the associated challenges, working together with the industrial partner. Indeed, "unlike other research methods, where the researcher seeks to study organizational phenomena but not to change them, the action researcher is concerned to create organizational change and simultaneously to study the process" (Baskerville and Myers, 2004). Thus, action research appears to be the best research method for this project since the internal resources of the industrial partner in terms of BIM and LPS were very limited and the involvement of the researcher was necessary. The principal researcher was then involved in all the steps of the project and directly worked on the scenario, the selection of the pilot project, the preparation of the BIM model and the conduct of the indoor simulation sessions. When necessary, an expert consultant in Lean Construction was involved in the project, in order to help in the development of the new planning and control processes.

The overall methodological structure consists of four stages: the identification of the problem, the establishment of a plan of action, the implementation of the action, the evaluation of the effects of the action (See Fig. 2).
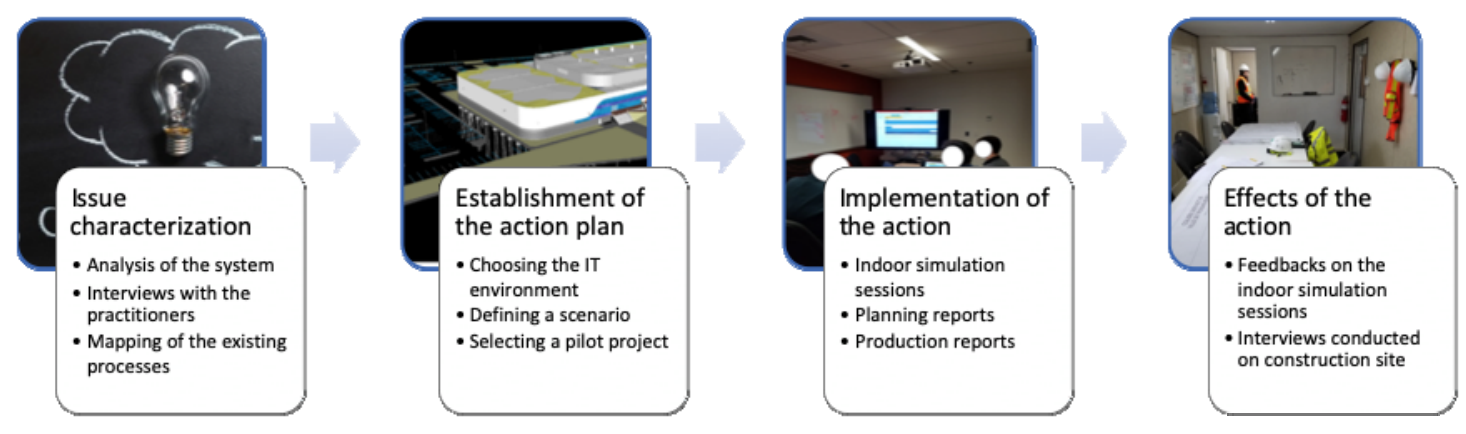

Fig. 2 Overview of the steps of the research.

The analysis of existing processes used by the industrial partner highlighted some gaps to cover by the implementation of a new technological tool that combines LPS and BIM. The industrial partner is a general contractor based in Montreal (Quebec, Canada), with more than thirty years of experience in the construction of institutional, commercial, industrial and residential buildings. The company has a workforce of approximately one hundred employees. To understand the context and the needs, an analysis of the planning and production practices as well as interviews with the involved actors was necessary. The analysis performed allows to understand and to map the existing processes, in collaboration with the representatives of the industrial partner. Interviews with practitioners on the 
construction site (Project Manager, Superintendent, Planner, and Assistant Project Manager) were also conducted, intending to assess the level of confidence and use of mobile technologies in the construction projects, and to assess shortcomings in the monitoring of the existing schedule and the control of production. Elements of solutions are thus identified to fill the gaps observed.

The action plan established as part of this research consists of the following steps: Choosing a solution, defining a scenario, choosing a pilot project, implementing the solution and gathering feedback from project stakeholders. The choice of the solution is made based on selection criteria coming from a synthesis of the literature, including the BIM features (3D visualization, 4D scheduling), LPS features (master scheduling, phase scheduling, lookahead planning, weekly work plan), collaboration and interoperability features (supported import and export formats), usability (user interface, ease of use), and accessibility (supported language, price).

The scenario adopted consists of a preliminary step of training the participants, and organizing an indoor simulation on the operation and use of the software, and to define with the participants an action plan for the use of the solution on the construction site. Thus, the project team (project director, project control manager, planners, project manager, superintendents, assistant project manager) is invited to participate in a demonstration session of the Leapcon serious game for duration of more than two (2) hours. The objective is to simulate the construction of a housing unit in traditional mode and LPS mode. The goal is to increase their awareness of the LPS while demonstrating the difference between pushed and pulled flows.

A pilot project was selected to test the software, relating to the construction of a sports centre and whose structure consists of steel and reinforced concrete elements (Fig. 3). The project lasts two years (from February 2018 to January 2020) and is carried out in the province of Quebec. The project is realized in turnkey mode and Fast Track mode. The practitioners' feedbacks were collected through semi-directive interviews.

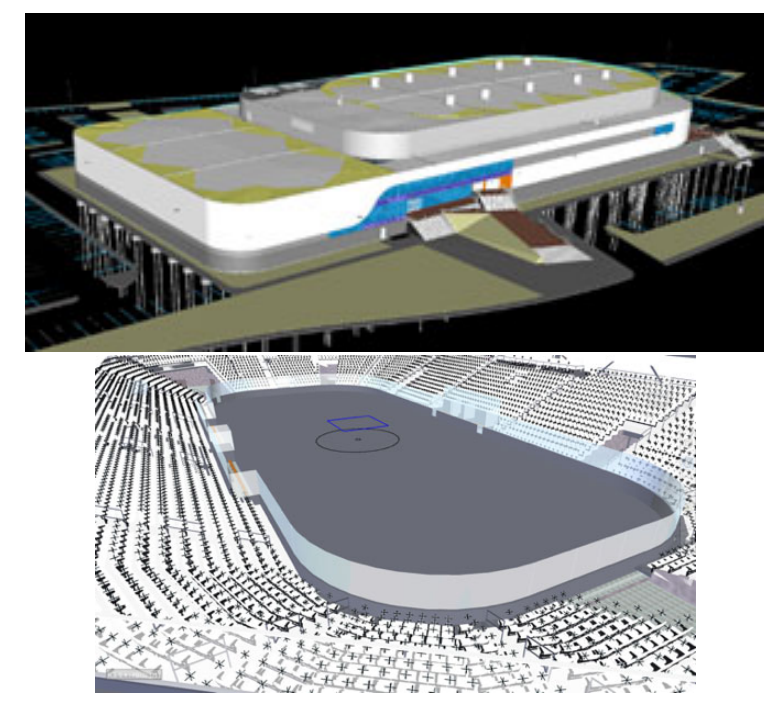

Fig. 3 Exterior and interior views of the building.

The collection of the feedbacks has been done in two separate steps: in the first step, the feedbacks from the pilot project team on their perception of the software were collected after the simulation of the use of the software. The software simulation took approximately one hour for the first meeting and approximately two hours for the second meeting. At the end of the software simulation, users provide feedback on their perception of the software. The participants were limited to the management team and the construction team consisting of the project manager, the assistant project manager, the superintendents, the project control officer, and the planning officers. A software implementation 
readiness questionnaire is used to interview the project manager, the associate project manager and the superintendent. The questionnaire is organized into three main sections. The first section is related to the existing processes and the needs for change. The second section is related to the perceived usages and added value of the software. The third part is related to the firm's readiness, including the internal competences in using BIM, LPS, and mobile technologies.

The second step consists in clarifying the results of the first step, by going to the site of three different construction projects including the pilot project, by attending the planning and coordination meetings, and by interviewing, at the end of these meetings, some selected professionals (see Table 1). It has been decided to interview all the practitioners directly involved in the use of the software, both in office and on construction site in order to have different perspectives of the situation. This encompasses the project manager, the assistant project manager, the superintendent, and the planning officer. Another questionnaire, on the use of the LPS / BIM software, is used at this stage. The topics discussed are about LPS knowledge (1), familiarity with BIM (2), access to information (3), collaborative planning (4), mobile technologies (5), change management (6), and site coordination (7), as synthesized in Table 1.

Table 1 Details of the interviews with the discussed subjects

\begin{tabular}{|c|c|c|c|c|c|c|c|c|c|}
\hline \multirow[t]{2}{*}{ Interviews } & \multirow[t]{2}{*}{ Interviewees } & \multirow[t]{2}{*}{ Dates } & \multicolumn{7}{|c|}{ Subjects } \\
\hline & & & (1) & (2) & (3) & (4) & (5) & (6) & (7) \\
\hline$\# 1$ & Project manager & 2018-11-06 & & & & $\mathrm{X}$ & $\mathrm{X}$ & $\mathrm{X}$ & \\
\hline$\# 2$ & Assistant project manager & $2018-11-06$ & $\mathrm{X}$ & $\mathrm{X}$ & $\mathrm{X}$ & & $\mathrm{X}$ & $\mathrm{X}$ & $\bar{X}$ \\
\hline$\# 3$ & Superintendent & $2018-11-06$ & & & & $\mathrm{X}$ & $\mathrm{X}$ & $\mathrm{X}$ & $\mathrm{X}$ \\
\hline$\# 4$ & Project manager & 2018-11-07 & $\mathrm{X}$ & $\mathrm{X}$ & $\mathrm{X}$ & & & & \\
\hline$\# 5$ & Planning officer & $2018-11-07$ & $\mathrm{X}$ & & & $\mathrm{X}$ & & $\mathrm{X}$ & \\
\hline \#6 & Superintendent & $2018-11-08$ & $\mathrm{X}$ & $\mathrm{X}$ & $\mathrm{X}$ & & & & $\mathrm{X}$ \\
\hline$\# 7$ & Project manager & $2018-11-08$ & & & & & & & $\mathrm{X}$ \\
\hline
\end{tabular}

\section{Main results}

\subsection{The existing situation and the needs}

In this section, we present the current situation through existing practices in planning, production control, and BIM use. The observations presented make it possible to focus on the need to improve and update existing processes, using LPS-BIM software.

The project team uses a traditional planning mode. Once the work to be done is designed by the designer's team, 3D designs are sent to the planner. He, in collaboration with the construction team and part of the project management team, produces a master schedule, using Primavera, Microsoft Project, or Microsoft Excel. This schedule is then submitted to the construction team for constructability verification. If the verification is satisfactory, the master schedule is adopted, and a copy is sent to the specialized contractors to get them to establish a construction schedule. A 'Lookahead Schedule' is also produced from the master schedule by the planner. The project team meets once a week to discuss progress, and planning of the future business. The drawings are displayed on the meeting table and are regularly consulted by the construction team and the specialized contractors. On a side of the wall appears a dashboard that serves as a support for displaying sequences of intervention of specialized contractors for a given period. On the opposite side of the wall is also an empty dashboard. However, a copy of the schedule is posted in the next room that serves as the Project Authority's office. There are also two dashboards present in the meeting room that are used by the construction team to relay 
information about the project. Specialist contractors are consulted sporadically when setting the master schedule. The master schedule is updated once a month by the planner. The construction team takes care of the planning/schedule control. Any change or modification of the schedule is reported to the planner by the construction team. Depending on the nature of the modifications, the master schedule is updated. The reference 'Baseline' schedule of ninety days (3 months) is drawn from this master schedule, and is sent to the client.

The existing production control process involves the specialized contractors, the management team, the controller, the professionals, and the client. The work performed by the specialized contractors is subject to the controls of the design and the construction management teams. A payment request issued by the specialized contractors is sent to the supervisor once the work is approved. The controller verifies that the contractual obligations have been fulfilled before forwarding the payment request to the accounting for payment. Otherwise, the specialized contractors are required to comply and resubmit the payment request. The control manager will also submit a payment request issued by the general contractor to the client. The professional verifies that the work was actually performed as specified in the contract. The payment order is then given by the customer as soon as the checks made by the professional are satisfactory.

The 3D models used are designed using Revit, and are aggregated and coordinated in Navisworks. The federated 3D model is then added to the Procore project management platform. This platform is accessible by all actors involved in the project. The site team uses mobile devices (laptop, iPad, smartphone) to access the available project documents on the platform. The general contractor uses the model to extract specific material quantities and to establish the master schedule. The construction team uses it to perform conflict and clash detection and $3 \mathrm{D}$ visualization of the project. A BIM Manager is responsible for updating the drawings, 3D model and other project documents on the Procore platform. This platform also makes it possible to display the results on the progress of work on the site.

\subsection{Choosing new tools to improve production planning and control}

The industrial partner is facing problems related to the limitations of traditional methods of planning and controlling production. The current planning method is traditional (Push Planning) and its practice generates difficulties such as the delay in the delivery of the works, the waste, and a decrease in productivity. As seen, the master schedule is designed in general without much contribution from the specialized contractors. The visualization of the schedule in BIM 4D is not yet adopted by the industrial partner. Certainly, there are important advances in terms of information sharing through the Procore project management platform, since all the reports and the drawings are accessible through this platform. The need for new tools integrating BIM and LPS comes from the desire of the industrial partner to improve its production planning and control. But such integration should not be limited to software tools alone, but should take into account the need to update current processes, in order to create a propitious context for the successful implementation of the software on construction sites.

Following the analysis of the planning software integrating LPS and BIM, and according to the identified selection criteria, the two selected softwares are BIM 360 Plan and VisiLean. Admittedly, the two programs are similar and make it possible to perform collaborative planning and production control with different approaches. However, BIM 360 Plan looks a lot more at collaborative planning while VisiLean has an additional function which offers a visualization of the elements of the project through the 3D model. It has been decided to test and to evaluate the BIM 360 Plan for production planning and VisiLean for production control.

In this logic, the planning process (Fig. 4) is divided into three phases: preliminary planning, planning integrating the LPS, and the use of the BIM 360 Plan. The preliminary planning is done in collaboration with the construction team and the planner. They use the drawings and the $3 \mathrm{D}$ model to 
generate a preliminary schedule. The schedule integrating the LPS is done in collaboration with the construction team, the planner, and all the specialized contractors. They refer to the preliminary schedule, the 3D drawings, and models to produce a schedule according to the LPS approach. The use of BIM 360 Plan converts the schedule defined according to the LPS approach into 'Milestone Breakdown Structure', and proposes an electronic version of the detailed schedule and the lookahead Schedule. The 'Weekly Work Plan' and the 'Daily Work Plan / Coordination' are generated by the software. The construction team must ensure that all specialized contractors have access to the software so that they can plan to perform the tasks to which they are committed.

Regarding the production control using VisiLean, a working process has also been proposed (Fig. 5). Before starting the execution of the tasks that the specialized contractors must carry out a constraint analysis 'Constraint Removal', this allows them to make the task ready to be executed (Task Make Ready). The software calculates the weekly Percent Plan Complete (PPC) for each specialized contractor. The construction team having access to the software can consult the progress of the work of each specialized contractor, and ensure by a physical verification in the field if the work is compliant or does not comply. The PPC produced by each specialized contractor, in addition to physical verification, can help the validation of the payment request of the specialized contractors. The Project Control Manager also has access to the software. This allows him not only to monitor the progress of the work of the specialized contractors, but also to know the overall progress of the work of the general contractor (by consulting the PPC to date). An instant notification system informs all project stakeholders of changes. The control manager and the management team are informed daily of the status of the project. The verification and the validation of the payment requests of the specialized contractors and the general contractor are made easy. For this preliminary case study on issues related to the implementation, we limited the research to the specialized contractors and the general contractor as participants.

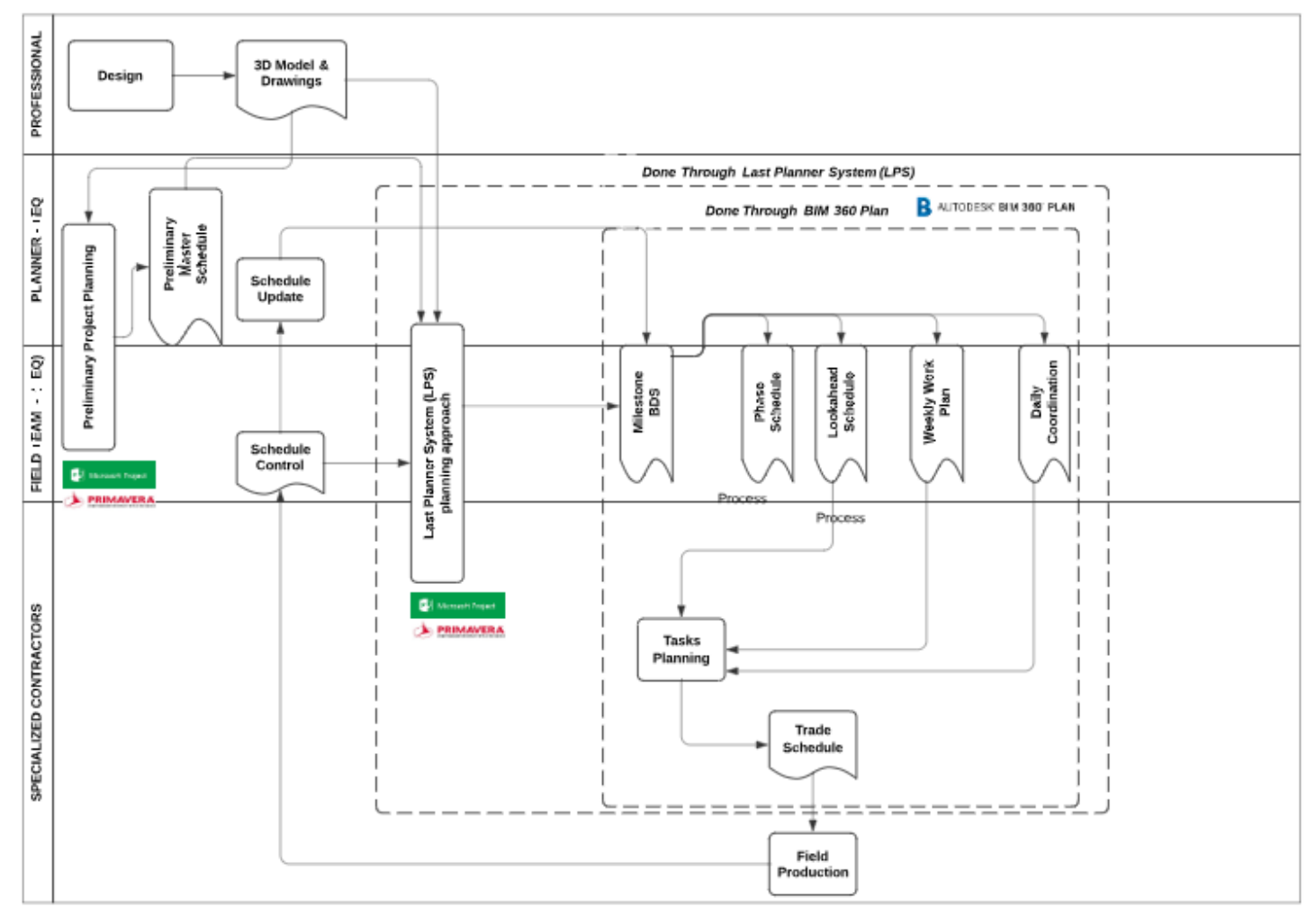

Fig. 4 Planning process, with BIM 360 Plan. 


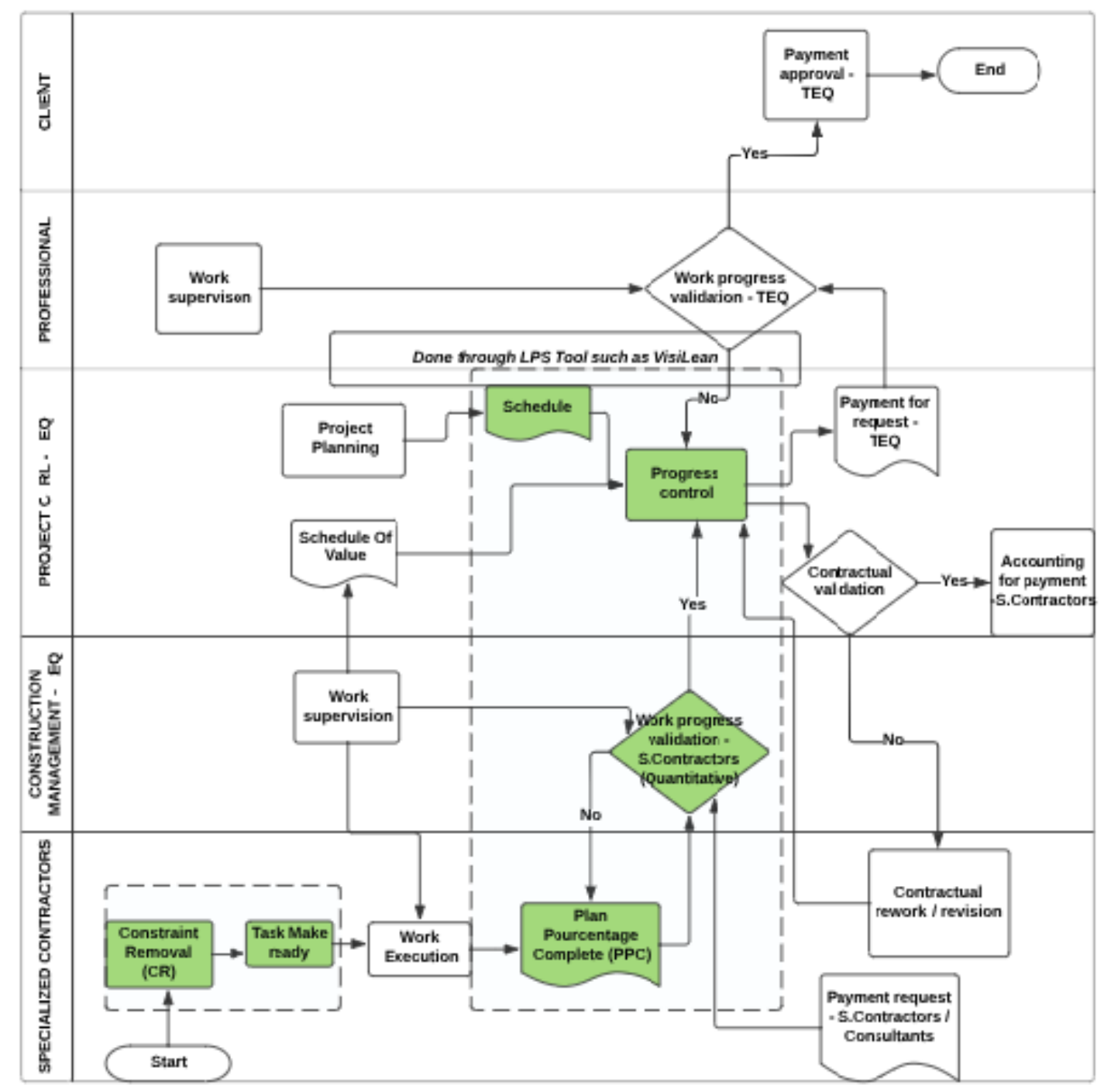

Fig. 5 Control process, with VisiLean.

\subsection{The main challenges}

The study showed a contradiction of point of view between the top management and the site team. The top management manifests the need to innovate and supports the idea of implementing the software. For the top management, such an implementation can be useful not only to optimize the planning process, but also to enable a variety of new usages. For example, using the software can help in "exploring the capability to leverage the PPC report data to facilitate the payment of subcontractors", said the project director at an introductory meeting. Moreover, the top management was keen to reduce delays when performing the site work. "Can an alert be triggered when an activity is late compared to its due date?" asked the project director. However, the construction team has an opinion contrary to that of top management. It finds that the adoption of this software means an additional constraint. The construction team finds it difficult, if not impossible, to get the cooperation of all the specialized contractors as the assistant project manager testifies: "It will be impossible to use in the field because all the employees are busy and specialized contractors will not be able to collaborate". "Superintendents and representatives of subcontractors will have a hard time accepting to use it because the software increases the volume of work", he adds. Throughout the participant interviews, participants expressed doubt about the operation and effectiveness of this new software. The site team 
showed strong opposition to the implementation of the tool. For $70 \%$ of participants, the hesitation and the doubt are justified by the lack of knowledge and experience on the software. For $30 \%$ of participants, reluctance to adopt a new, little-known approach creates resistance to change. They find that it is risky to rely entirely on technology. "When the system does not work after an internet interruption or technical failure, it delays our work and we are wasting time", the superintendent stated. Among the barriers expressed by the site team, the lack of knowledge is frequently mentioned in interviews. Eight out of ten participants (80\%) do not know the LPS; however, the 10 respondents say they know BIM. This lack of knowledge is justified by the fact that the LPS is a new concept for many construction companies. However, encouraging feedbacks have been received from the planner: "We would like to adopt the LPS if it is an approach that will simplify our planning", he says. For successful adoption of the LPS, it is important to train the workers and to show them the added value of this approach. The need for training was raised by each of the interview participants. It is important to set up a continuing education program for software users, in both LPS and BIM. The testimonials gathered are of the same opinion as that of the project manager. "I think that we must train workers to hope to successfully implement the software combining LPS and BIM, and require its use in contractual clauses", he says. The Superintendent draws on his experience with implementing BIM to emphasize the importance of worker training. "BIM is a very good tool, but workers do not know how to use it", he concludes.

Throughout the interviews, participants expressed doubt about the operation and effectiveness of this new software. For $70 \%$ of participants (seven out of 10 ), hesitation and doubt are justified by the lack of knowledge and experience on the software. For $30 \%$ of participants (three out of ten), reluctance to adopt a new, and little-known approach creates resistance to change. They find that it is risky to rely entirely on TM, as the Superintendent testifies, "When the system does not work after an internet interruption or technical failure, it delays our work and we are wasting time. Having a full-time person in the field for technical assistance and ongoing training of software users can simplify the software adoption, and can motivate and encourage workers to use the software well. The superintendent's testimony supports the need to have a champion assigned to the project "This is a good opportunity, but it will be difficult to implement if a resource responsible for the tool is not recruited to conduct the implementation ". The project manager is of the same opinion. "Not having a person dedicated to the management of the documentation makes the work of the project manager quite painful when searching for documents. [...] We must also recruit a person in full time who will take care of the daily training of users and the use of LPS and BIM software throughout the project", he says.

In addition, the research highlights several key success factors. For effective implementation, it is important:

- $\quad$ to obtain client approval and ensure continued support from top management and include in the contracts with subcontractors the use of LPS techniques for collaborative planning;

- $\quad$ to appoint or recruit a champion or coordinator who is responsible for providing ongoing training and technical support to users, and develop and execute a continuous training program for the users;

- to establish a committee that is in charge of the adoption, clearly define the objectives to be achieved, and make sure to involve as much as possible all the stakeholders in the process;

- $\quad$ to evaluate and communicate regularly the progress achieved by the team, and facilitate the visualization of the results by displaying them on the walls of the meeting rooms at the construction site;

- $\quad$ to provide a large touch screen in the meeting room at the worksite to allow visualization of the schedule and the 3D model during planning and coordination meetings. 


\section{Discussion and conclusion}

The research presented in this paper aims at exploring the main challenges to overcome in order to successfully implement a software combining BIM and Last Planner System on a construction site. Compared to recent related studies, the research is less enthusiastic: Implementing such a software is less easy than expected. Indeed, despite the obvious and demonstrated complementarity between the two approaches, several challenges must be overcome before successful implementation can be achieved. The results highlight the need for new tools to improve production planning and control, but also points to a strong resistance to change by practitioners at the site. They emphasize the necessity for adequate pre-service training and the need for new resources that can work full-time on the ongoing training of site teams. In addition, some limitations of the tool lead workers to believe that it can quickly become a factor that slows down their daily work rather than improving it. As can be seen, the issues identified largely relate to worker familiarity with BIM and Lean approaches, and to limitations of selected software. However, these issues are in fact micro-level challenges. To fully understand the challenges related to implementing a software that combines BIM and Last Planner System, it is important to have a larger picture of the situation. Interestingly, the results show a contradiction of point of view between the top management (more optimistic) and the site team (less optimistic). Such a contradiction contains important clues to understanding the macro-level perspective within the company. Indeed, the top management, in its optimistic attitude seems to downplay the important role it must play for the success of the implementation, which must above all be based on a good strategic alignment between business practices and information technology. The alignment between information technologies (IT) and business practices has been "a top concern" in the Information Technologies communities over the last decades (Pekkola and Nieminen, 2015). Three main forms of alignment have been identified: functional alignment (Henderson and Venkatraman, 1990), structural alignment (Broadbent and Weill, 1993) and dynamic alignment (Sabherwal et al., 2001). The functional alignment is related to enhancing business capabilities by the mean of IT resources, while the structural alignment focuses on how to align IT and business decisions across the organization (Pekkola and Nieminen, 2015). Dynamic alignment refers to the effects of today's strategic decisions on the decision options in the future (Pekkola and Nieminen, 2015). Various models have been proposed to support each of these forms of alignment ( Henderson and Venkatraman, 1990; Broadbent and Weill, 1993; Sabherwal et al., 2001) and the role of the top management is critical as it can act at the strategic level. In the specific case of the BIM approach, "there must be support from the senior hierarchy as well as a practical method for change management" (Boton and Forgues, 2018).

A major limitation of the work is that it was conducted on a single project. It would be interesting in the future to extend the scope of the study to a larger number of projects, with different contexts and characteristics. This would make it possible to evaluate which of these challenges are generalizable and which ones are specific to the project studied. In addition, an important factor in the success of the combination lies in the optimization of the flow of information between the design teams and the construction teams. This aspect has not really been addressed in the research work and deserves to be addressed in more detail. Future works will focus on extending the scope of the research and on how to optimize the continuum of information between the design team and the construction site, in order to fully benefit from the capabilities offered by BIM models.

\section{References}

AlSehaimi A O, Tzortzopoulos Fazenda P, Koskela L (2014). Improving construction management practice with the Last Planner System: A case study. Engineering, Construction and Architectural Management, 21(1): 51-64

Arayici Y, Coates P, Koskela L, Kagioglou M, Usher C, O’Reilly K (2011a). BIM adoption and implementation for architectural practices. Structural Survey, 29(1): 7-25 
Arayici Y, Coates P, Koskela L, Kagioglou M, Usher C, O’Reilly K (2011b). Technology adoption in the BIM implementation for lean architectural practice. Automation in Construction, 20(2): 189-195

Ballard G, Howell G (1997). Toward construction JIT. In: Alarcón L F, eds. Lean Construction. Rotterdam: Balkema, 291-300

Ballard G, Howell G (2004). An update on Last Planner. In: Proceedings of the 11th Annual Conference of the International Group for Lean Construction, Virginia, USA

Ballard H G (1994). The Last Planner. In: Spring Conference of the Northern California Construction Institute, Monterey, CA

Ballard H G (2000). The Last Planner System of production control. Dissertation for the Doctoral Degree. Birmingham:University of Birmingham

Baskerville R, Myers M D (2004). Special issue on action research in information systems: Making IS research relevant to practice: Foreword. MIS Quarterly, 28(3): 329-335

Berroir F, Harbouche L, Boton C (2015). Top down vs. bottom up approaches regarding the implementation of Lean construction through a French case study. In: Proc. 23rd Annual Conference of the International Group for Lean Construction. Perth, Australia, 73-82

Bilandzic M, Venable J (2011). Towards participatory action design research: Adapting action research and design science research methods for urban informatics. The Journal of Community Informatics, 7(3): $1-17$

Boton C, Rivest L, Forgues D, Jupp J (2016). Comparing PLM and BIM from the product structure standpoint. In: IFIP Advances in Information and Communication Technology (Vol. 492). Berlin: Springer

Boton C, Forgues D (2018). Practices and processes in BIM Projects: An exploratory case study. Advances in Civil Engineering, 1-12

Boton C, Forgues D, Halin G (2018a). A framework for Building Information Modeling implementation in engineering education. Canadian Journal of Civil Engineering, 45(10): 866-877

Boton C, Halin G, Kubicki S (2012). A metamodel to describe nD CAD visualization as coordinated multiple views. In: Luo Y, eds. CDVE2012, LNCS 7467. Osaka, Japa: Springer Berlin Heidelberg, 219-226

Boton C, Kubicki S, Halin G (2013). Designing adapted visualization for collaborative 4D applications. Automation in Construction, 36: 152-167

Boton C, Rivest L, Forgues D, Jupp J R (2018b). Comparison of shipbuilding and construction industries from the product structure standpoint. International Journal of Product Lifecycle Management, 11(3): 191-220

Broadbent M, Weill P (1993). Improving business and information strategy alignment: Learning from the banking industry. IBM Systems Journal, 32(1): 162-179

Cheng Y M (2014). An exploration into cost-influencing factors on construction projects. International Journal of Project Management, 32(5): 850-860

Clemente J, Cachadinha N (2013). Bim-lean synergies in the management on mep works in public facilities of intensive use - A case study. In: 21st Annual Conference of the International Group for Lean Construction (IGLC 21), 751-760

Dave B, Koskela L J (2011). Visilean: Designing a production management system with lean and BIM. In: Proceedings of the 19th conference of the International Group for Lean Construction

Dave B, Boddy S, Koskela L (2013). Challenges and opportunities in implementing Lean and BIM on an infrastructure project. 21st Annual Conference of the International Group for Lean Construction 2013 (IGLC 2013), 60-69

Doloi H (2012). Cost overruns and failure in project management: Understanding the roles of key stakeholders in construction projects. Journal of Construction Engineering and Management, 
139(3): 267-279

Fosse R, Ballard G, Fischer M (2017). Virtual design and construction - Aligning BIM and Lean in practice. In: 25th Annual Conference of the International Group for Lean Construction, 499-506

Gao S, Low S P (2014). Lean Construction Management: The Toyota Way. Berlin: Springer

Hamdi O, Leite F (2012). BIM and Lean interactions from the bim capability maturity model perspective: A case study. IGLC 2012 - 20th Conference of the International Group for Lean Construction

Hamzeh F R, Zankoul E, Rouhana C (2015). How can ‘tasks made ready' during lookahead planning impact reliable workflow and project duration? Construction Management and Economics, 33(4): 243-258

Henderson J, Venkatraman N (1990). Strategic alignment: A model for organizational transformation via information technology. Massachusetts Institute of Technology, 1-48

Khan S, Tzortzopoulos P (2014). Effects of the interactions between LPS and BIM on workflow in two building design projects. Proceedings for the 22nd Annual Conference of the International Group for Lean Construction, 1(321): 933-944

Koskela L, Howell G, Ballard G, Tommelein I (2002). The foundations of Lean construction. In: Best $\mathrm{R}$, de Valence G, eds. Design and Construction: Building in Value. Woburn, MA: Butterworth-Heinemann, 211-226

Lee A, Aouad G, Cooper R, Fu C, Marshall-Ponting A, Tah J, Wu S (2005). nD modelling-a driver or enabler for construction improvement? RICS Research Paper Series, 5(6): 1-16

Naoum S G (2016). Factors influencing labor productivity on construction sites. International Journal of Productivity and Performance Management, 65(3): 401-421

Pekkola S, Nieminen N (2015). Comparison of functional, structural, and dynamic business-IT alignment models: A case study. In: Proceedings of the 21st Americas Conference on Information Systems (AMCIS) 2015, 1-14

Pitti Y, Boton C, Forgues D (2019). Combining BIM and Last Planner on construction sites: An investigation of the related challenges. In: Skibniewski M J, Hajdu M, eds. Proceedings of the Creative Construction Conference. Budapest, Hungary, 824-829

Poirier E, Forgues D, Staub-French S (2016). Collaboration through innovation: Implications for expertise in the AEC sector. Construction Management and Economics, 34(11): 769-789

Rafael S, Eastman C, Lee G, Paul T (2018). BIM Handbook: A Guide to Building Information Modeling for Owners, Designers, Engineers, Contractors, and Facility Managers, Third Edition. Hoboken, New Jersey: Wiley

Rahman I A, Memon A H, Karim A T A (2013). Significant factors causing cost overruns in large construction projects in Malaysia. Journal of Applied Sciences, 13(2): 286-293

Sabherwal R, Hirschheim R, Goles T (2001). The dynamics of alignment: Insights from a punctuated equilibrium model. Organization Science, 12(2): 179-197

Sacks R, Koskela L, Dave B A, Owen R (2010). Interaction of Lean and Building Information Modeling in construction. ASCE Journal of Computing in Civil Engineering, 136: 968-980

Saieg P, Sotelino E D, Nascimento D, Caiado R G G (2018). Interactions of Building Information Modeling, Lean and sustainability on the architectural, engineering and construction industry: A systematic review. Journal of Cleaner Production, 174: 788-806

Seppänen O, Ballard G, Pesonen S (2010). The combination of Last Planner system and location-based management system. Lean Construction Journal, 43-54

Shelbourn M, Bouchlaghem N M, Anumba C, Carrillo P (2007). Planning and implementation of effective collaboration in construction projects. Construction Innovation, 7(4): 357-377

Tauriainen M, Marttinen P, Dave B, Koskela L (2016). BIM and Lean construction change design management practices. Creative Construction Conference 2016, 668-673 
Teicholz P (2013). Labor-productivity declines in the construction industry: Causes and remedies (another look). ACE Bytes

The Computer Integrated Construction Reseaerch Program (2010). Building Information Modeling execution planning guide. A BuildingSMART Alliancetm Project. The Pennsylvania State University: Computer Integrated Construction Research Group

Vigneault M -A, Boton C, Chong H -Y, Cooper-Cooke B (2019). An innovative framework of 5D BIM solutions for construction cost management: A systematic review. Archives of Computational Methods in Engineering, 1-18 